\title{
Study on Overburden Rock Movement and Stress Distribution Characteristics under the Influence of a Normal Fault
}

\author{
Quansen Wu $\mathbb{D}^{1},{ }^{1}$ Peng Kong $\mathbb{D},{ }^{2}$ Quanlin Wu, ${ }^{1}$ Xinggang Xu, ${ }^{2}$ Xingyu Wu $\mathbb{D}^{\circ},{ }^{2}$ and Tao Guo ${ }^{2}$ \\ ${ }^{1}$ Jining University, Jining 273100, China \\ ${ }^{2}$ State Key Laboratory of Mining Disaster Prevention and Control, Shandong University of Science and Technology, \\ Qingdao 266590, China
}

Correspondence should be addressed to Peng Kong; 17854859770@163.com

Received 1 February 2020; Revised 22 July 2020; Accepted 21 August 2020; Published 19 September 2020

Academic Editor: Daniele Baraldi

Copyright (C) 2020 Quansen Wu et al. This is an open access article distributed under the Creative Commons Attribution License, which permits unrestricted use, distribution, and reproduction in any medium, provided the original work is properly cited.

Fault activation triggers local deformation and dislocation, releasing a large amount of energy that can easily cause mining disasters, such as rock bursts and roadway instability. To study the changing characteristics of overburden structures and the evolution law of mining-induced stress as panel advances towards a fault from a footwall, two similar models were established, namely, a simulation experimental model and a numerical simulation model. In addition, the relationship among mining, mining stress, and rock bursts induced by fault activation was investigated. The results of this study reveal that when the working face is $30 \mathrm{~m}$ away from the fault, the high-position rock mass near the fault turns to the goaf where the fault is activated, and the two walls display relatively obvious dislocation. During the process of footwall panel mining to the fault, the abutment stress of the coal pillar tends to increase initially, followed by a decrease. When the working face is $20 \mathrm{~m}$ away from the fault, the abutment stress ahead of the working face reaches its maximum. When the width of the coal pillar is within the range of 10-40 m, the coal pillar accumulates a large amount of energy, and the working face affected by the fault easily induces a rock burst. Before fault activation, disturbances arising from the mining activities destroy the equilibrium stress environment of the rock system surrounding the fault, and the fault continuously accumulates energy. When the accumulated energy reaches a certain threshold, under the action of normal stress or shear stress, the fault will be activated, and a large amount of energy will be released, which can easily induce a rock burst. The research results in this paper provide a scientific basis for the classification, prediction, and prevention of rock bursts under similar geological conditions.

\section{Introduction}

Coal is the main energy source in the world, playing an irreplaceable role in the development of the world economy $[1,2]$. With the rapid development of the economy, the demand for coal and improved production capacity are increasing, and the geological conditions of the coal mines are becoming increasingly complicated [3-5]. In most areas of China, the mine geological conditions are complex, and the geological structure is highly developed. In terms of underground geological structures, faults are the most common structures, and they have a significant impact on the mining design and layout and safety during production, as well as mining panel technology [6-8]. These faults were stable before being affected by mining. As the mining activity approaches the fault, the originally stable fault becomes disrupted due to the barrier effect, cutting open the originally "cemented" fault surface and allowing the hanging wall and footwall of the fault to slip, inducing fault activation [9]. Production practices and monitoring analyses show that faults have an essential influence on the distribution of abutment stress and dynamic phenomena of the panel, and the slipping of faults due to mining may induce geological disasters such as rock bursts, mine earthquakes, large roadway deformations, and coal and gas outbursts, seriously affecting the safety of coal mines [10-13]. In addition, the data show that rock bursts caused by faults and other geological structural factors account for $64.18 \%$ of all rock 
burst accidents in China [14]. For example, among the rock burst accidents in the Longfeng Coal Mine, $72 \%$ were related to faults, with $62 \%$ occurring when the roadway was near a fault. The occurrence of a rock burst can cause serious roadway deformation and instability. Microseismic monitoring and analysis of Panel 3201 of the Chaoyang Coal Mine in Shandong Province revealed that microseismic events were concentrated mainly near the fault in front of the working face. Under the influence of fault activation in the tunneling process of Panel 21221 of the Qianqiu Coal Mine, an extremely large rock burst accident occurred, which resulted in the destruction of over $400 \mathrm{~m}$ of roadway, serious damage to the anchor wire, and severe contraction of the roadway section (as shown in Figure 1), severely affecting the safety and efficiency of the coal mine [15]. Therefore, fault instability has become an important factor associated with the occurrence of geological disasters in mines. The study of rock bursts influenced by faults has become an urgent problem that needs to be solved to ensure safe mining.

Presently, many experts have extensively researched the problems associated with mining near faults using numerical analyses, similar simulation tests, laboratory tests, theoretical analyses, and field measurements. Li et al. studied rock burst mechanisms through theoretical analyses, laboratory tests, numerical simulations, and engineering practices and established a mechanical model for the instability of fault coal pillars [6]. Wang et al. [16], Peng et al. [17], and Liu et al. [18] studied the failure and stress distribution of the overburden affected by the fault and obtained the caving height of the roof and the stresses on the coal body (which were large), showing that the footwall panel advanced towards the fault. Quan-sen et al. [10] used numerical simulation to analyze fault slip and fault energy evolution characteristics as a panel advanced towards a normal fault. The accumulated energy of the fault gradually increased, and a large amount of energy was rapidly released during the instability activation of the fault; this release of energy could easily induce dynamic disasters such as rock bursts or mine earthquakes. Sainoki et al. [6, 19-21] performed numerous studies on rock bursts induced by fault slips. In their work, the Barton shear strength model was embedded into the FLAC3D simulation via the secondary development of a numerical simulation to analyze the rock burst induced by fault instability under the roughness fault plane. The results of their study showed that the probability of high-energy seismic events with a rough contact surface was greater than the probability of high-energy seismic events with a smooth contact surface. Li et al. [22, 23] used theoretical analysis, numerical simulation, and engineering examples to study the mechanism of rock bursts in fault-affected areas, established a mechanical model of fault latching and unlocking, and derived a judgment formula to unlock the fault. The concept of coal pillar rock bursts in a fault-affected zone was proposed. Based on the analysis of the distribution law of source in site, the authors concluded that the rock burst was induced by fault slip, roof fracture, and coal pillar destruction. Zhang et al. [24] developed a new similar solid-fluid coupling material and conducted a feasibility analysis of the simulated materials to study the expansion activation of concealed faults. Meng Zhaoping, Duranda, Müller, Shi and Chen, Chen et al., and Lafont et al. $[11,25-32]$ used numerical simulation to study the distribution of abutment pressure in the panel near the fault and its influence on the stability of the roof, revealing the induced mechanism underlying the rock burst near the fault, which was based on the geological structure, microseismic activity, and stress field. The above studies focused mainly on the distribution of the abutment stress and fault activation under the influence of mining. In addition, most previous studies have used theoretical analysis and numerical simulation to study the characteristics of the abutment stress distribution during panel mining through a fault. However, the relationship among the movement structure of the overburden, the distribution of the abutment stress, and the potential of a rock burst under the influence of a fault has not been considered. Therefore, in this paper, the relationship among the overburden structure, distribution of the abutment stress, and fault activation during the process of footwall panel mining through a fault was studied using two methods, namely, a simulation test and numerical simulation. The movement of the roof when the footwall panel mined through the fault was intuitively reproduced by a simulation test. Then, the evolution characteristics of mining-induced stress as the working face advanced towards the fault direction were analyzed by numerical simulation. Finally, according to the results of the study, some reasonable suggestions were proposed for rock bursts induced by a fault slip. The research results in this paper provide a scientific basis for mining and preventing rock bursts under similar geological conditions.

\section{Similar Simulation Test Design}

2.1. Experimental Model Design. The selection of the test materials plays a decisive role in the success of the test, and the filling materials play an important role in the density, particle size, and strength of similar simulated materials. Cementing materials have a great influence on the strength, tensile strength to tensile strength ratio, and mechanical properties of similar materials. Thus, river sand was used as the filling material, and calcium carbonate and gypsum were used as the cementing materials $[33,34]$. In addition, mica powder was used to isolate each layer in the test to prevent the layers from becoming glued together due to pressure during the layering process. The size of the test model was $3000 \mathrm{~mm}$ (length) $\times 400 \mathrm{~mm}$ (width) $\times 1800 \mathrm{~mm}$ (height), the drop of the fault was $4 \mathrm{~m}$, the dip of the fault was $50^{\circ}$, and the thickness of the coal seam was $8 \mathrm{~m}$.

Similar simulation models and prototypes should follow certain similar conditions. The test should follow geometric similarity, time similarity, bulk density similarity, elastic modulus similarity, and strength similarity in the design process. The similarity ratio of the model parameters was determined according to the test requirements, and the similarity parameters are shown in Table 1 [15].

The lithology selection of the test model was based on the columnar chart of the No. 104 mining area of the Yangliu Coal Mine, and the lithology parameters were adjusted 


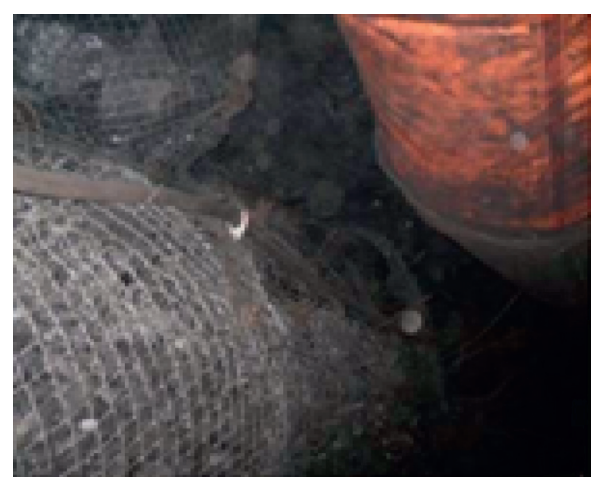

(a)

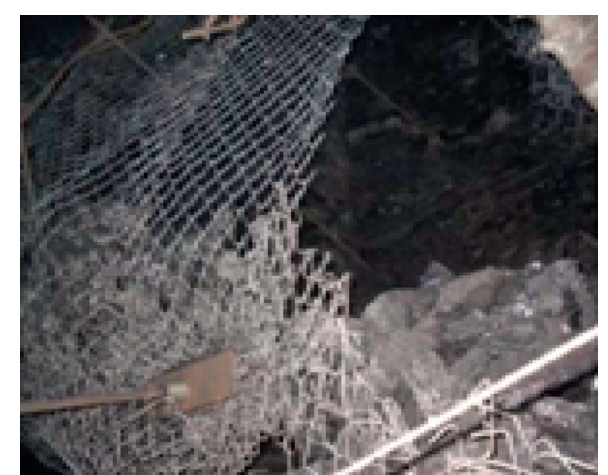

(b)

Figure 1: Damage to a roadway caused by a rock burst.

TABLE 1: Similarity parameters.

\begin{tabular}{lccccc}
\hline Similarity parameters & & & & \\
\hline Geometric & Time & Density & MOE & Strength & Poisson's ratio \\
200 & 14 & 1.5 & 300 & 300 & 1 \\
\hline
\end{tabular}

appropriately according to the test needs. According to the actual strength of the coal strata and similar simulation parameters, the simulated strength of the coal and rock mass in the test was obtained. According to the experiment, the uniaxial compressive strength of each rock layer was obtained, and the appropriate material ratio was selected according to the similarity ratio. Finally, the material ratio of each rock layer was calculated. The lithology of the overburden was composed mainly of mudstone, sandstone, and mud-sandstone interbedded with each other. Due to the repeated lithology, this paper lists the proportion of some of the materials, as shown in Table 2 [15].

2.2. Making Similar Material Simulation Models. During the layering process of the fault model, the dip of the fault is not easy to control. To better control the dip of the fault, a steel strip was designed to fix the dip of the fault. The steel strip was placed as shown in Figure 2 [15].

According to the predesigned material ratio and the layering height of the rock layer, an electronic scale was used to weigh and mix the materials evenly, to add a certain proportion of water, and finally, to combine the entire mixture evenly. In the layering process, the hanging wall and footwall of the fault were placed separately. First, the hanging wall was placed, and then the footwall was placed. In the test model, the throw of the fault was relatively small, and obvious scratches and slip planes occurred between the two walls. The fault plane was weak. Therefore, the fault plane was replaced by mica powder at a thickness of $1-2 \mathrm{~cm}$. The model is shown in Figure 3, and the placement of the fault zone is shown in Figure 4 [15].

\section{Analysis of Similar Simulation Test Results}

After natural air drying in the laboratory, the model was excavated from right to left. To eliminate the boundary effect, the $50 \mathrm{~m}$ coal pillar was left in place. The model was excavated $5 \mathrm{~cm}$ at a time and stopped 6 times per day. To ensure that the overburden strata collapsed fully, the interval time was at least $1.5-2.0 \mathrm{~h}$. The evolution rule of overburden movement during the mining process is shown in Figure 5. Figure 5 shows the failure pattern of the overburden structure when the working face is $140 \mathrm{~m}$ and $110 \mathrm{~m}$ away from the fault. This figure shows that when the working face is far away from the fault, the mining of the panel is not affected by the fault, the evolution characteristics of the overlying rock movement structure are a normal arch structure, and the separation layer develops in the transverse and vertical directions. When the working face is $110 \mathrm{~m}$ away from the fault, the first periodic rupture of the main roof occurs. The height of the separation layer in the vertical direction is $43 \mathrm{~m}$, and the span of the separation layer reaches $62 \mathrm{~m}$.

As Figure 5 shows, with the panel mined step by step, overburden separation in the vertical direction and the horizontal direction constantly expands. As shown in Figure 5(a), when the working face is $40 \mathrm{~m}$ away from the fault, the separation development height is $84 \mathrm{~m}$, the horizontal length is $63.6 \mathrm{~m}$, and the main roof periodic breakage occurs. The "three zone" characteristic development of the arch is normal. The fault has no effect on the horizontal growth of the fracture, and the near fault rock layer shows no obvious change. Figure 6(b) shows the fracture pattern of the overburden when the working face is $30 \mathrm{~m}$ away from the fault. As the goaf area increases, the distance between the horizontal transverse fractures and the fault decreases. The height of separation in the vertical direction is $122 \mathrm{~m}$ above the coal seam. Affected by the fault tendency and its cutting action, the higher position of the rock near the fault side turns towards the goaf, leading to a fracture in the fault zone. The maximum and minimum heights of the fracture in the fault are $130 \mathrm{~m}$ and $83 \mathrm{~m}$ above the coal seam, respectively. 
TABLE 2: Ratios and dosages of similarly simulated materials.

\begin{tabular}{|c|c|c|c|c|c|c|c|c|c|c|}
\hline \multirow{2}{*}{$\begin{array}{l}\text { Number of } \\
\text { strata }\end{array}$} & \multirow[b]{2}{*}{ Lithology } & \multirow{2}{*}{$\begin{array}{l}\text { Thickness } \\
(\mathrm{cm})\end{array}$} & \multirow{2}{*}{$\begin{array}{l}\text { Thickness of } \\
\text { layer }(\mathrm{cm})\end{array}$} & \multirow[b]{2}{*}{ Time } & \multirow{2}{*}{$\begin{array}{c}\text { Volume- } \\
\text { weight }\left(\mathrm{g} / \mathrm{m}^{3}\right)\end{array}$} & \multirow{2}{*}{$\begin{array}{l}\text { Ratio of } \\
\text { number }\end{array}$} & \multicolumn{4}{|c|}{ Material (kg) } \\
\hline & & & & & & & $\begin{array}{l}\text { River } \\
\text { sand }\end{array}$ & $\begin{array}{l}\text { Calcium } \\
\text { carbonate }\end{array}$ & Gypsum & Water \\
\hline $\mathrm{R}-20$ & Mudstone & 3 & 1.5 & 2 & 1.5 & 864 & 12.62 & 0.95 & 0.63 & 1.42 \\
\hline $\mathrm{R}-19$ & Packsand & 2.5 & 2.5 & 1 & 1.6 & 782 & 11.23 & 1.28 & 0.32 & 1.28 \\
\hline $\mathrm{R}-18$ & $\begin{array}{l}\text { Sandy } \\
\text { mudstone }\end{array}$ & 4 & 2 & 2 & 1.5 & 864 & 17.34 & 1.30 & 0.87 & 1.95 \\
\hline $\mathrm{R}-17$ & Gritstone & 2.5 & 2.5 & 1 & 1.6 & 773 & 11.63 & 1.16 & 0.50 & 1.33 \\
\hline $\mathrm{R}-16$ & Mudstone & 3 & 1.5 & 2 & 1.5 & 864 & 13.46 & 1.01 & 0.67 & 1.51 \\
\hline $\mathrm{R}-15$ & Siltstone & 3 & 1.5 & 2 & 1.6 & 755 & 14.35 & 1.03 & 1.03 & 1.64 \\
\hline $\mathrm{R}-14$ & $\begin{array}{c}\text { Silty } \\
\text { mudstone }\end{array}$ & 4 & 2 & 2 & 1.5 & 864 & 18.51 & 1.39 & 0.93 & 2.08 \\
\hline $\mathrm{R}-13$ & Siltstone & 2 & 2 & 1 & 1.6 & 755 & 9.91 & 0.71 & 0.71 & 1.13 \\
\hline $\mathrm{R}-12$ & Mudstone & 3 & 1.5 & 2 & 1.5 & 864 & 14.30 & 1.07 & 0.72 & 1.61 \\
\hline $\mathrm{R}-11$ & Siltstone & 4 & 2 & 2 & 1.6 & 755 & 20.31 & 1.45 & 1.45 & 2.32 \\
\hline $\mathrm{R}-10$ & Mudstone & 3 & 1.5 & 2 & 1.5 & 864 & 14.79 & 1.11 & 0.74 & 1.66 \\
\hline $\mathrm{R}-9$ & Siltstone & 2.5 & 2.5 & 1 & 1.6 & 755 & 13.12 & 0.94 & 0.94 & 1.5 \\
\hline $\mathrm{R}-8$ & Mudstone & 3 & 1.5 & 2 & 1.5 & 864 & 15.17 & 1.14 & 0.76 & 1.71 \\
\hline $\mathrm{R}-7$ & Siltstone & 2.5 & 2.5 & 1 & 1.6 & 755 & 13.46 & 0.96 & 0.96 & 1.54 \\
\hline $\mathrm{R}-6$ & Mudstone & 2.5 & 2.5 & 1 & 1.5 & 864 & 12.97 & 0.97 & 0.65 & 1.46 \\
\hline R-5 & Siltstone & 2 & 2 & 1 & 1.6 & 755 & 11.01 & 0.79 & 0.79 & 1.26 \\
\hline $\mathrm{R}-4$ & $\begin{array}{l}\text { Sandy } \\
\text { mudstone }\end{array}$ & 1.5 & 1.5 & 1 & 1.5 & 864 & 7.94 & 0.60 & 0.40 & 0.89 \\
\hline $\mathrm{R}-3$ & Siltstone & 2 & 1 & 1 & 1.6 & 755 & 11.18 & 0.80 & 0.80 & 1.28 \\
\hline $\mathrm{R}-2$ & Mudstone & 1.5 & 1.5 & 1 & 1.5 & 864 & 8.06 & 0.60 & 0.40 & 0.89 \\
\hline $\mathrm{R}-1$ & Packsand & 2 & 1 & 2 & 1.6 & 782 & 11.36 & 1.30 & 0.30 & 1.30 \\
\hline Coal & Coal & 4 & 2 & 2 & 1.6 & 864 & 16.36 & 1.23 & 0.82 & 1.84 \\
\hline F-1 & Gritstone & 1.5 & 1.5 & 1 & 1.6 & 773 & 8.70 & 0.87 & 0.37 & 0.99 \\
\hline $\mathrm{F}-2$ & $\begin{array}{c}\text { Sandy } \\
\text { mudstone }\end{array}$ & 2 & 2 & 1 & 1.5 & 864 & 11.12 & 0.83 & 0.56 & 1.25 \\
\hline F-3 & Packsand & 2.5 & 2.5 & 1 & 1.6 & 782 & 14.71 & 1.68 & 0.42 & 1.68 \\
\hline F-4 & Siltstone & 2 & 2 & 1 & 1.6 & 755 & 11.89 & 0.85 & 0.85 & 1.36 \\
\hline F-5 & $\begin{array}{c}\text { Sandy } \\
\text { mudstone }\end{array}$ & 2.5 & 2.5 & 1 & 1.5 & 864 & 14.28 & 1.07 & 0.71 & 1.61 \\
\hline F-6 & Packsand & 2 & 2 & 1 & 1.6 & 782 & 12.11 & 1.38 & 0.35 & 1.38 \\
\hline F-7 & $\begin{array}{l}\text { Sandy } \\
\text { mudstone }\end{array}$ & 4 & 2 & 2 & 1.5 & 864 & 23.26 & 1.74 & 1.16 & 2.62 \\
\hline F-8 & Siltstone & 2 & 2 & 1 & 1.6 & 755 & 12.41 & 0.89 & 0.89 & 1.42 \\
\hline F-9 & Gritstone & 4 & 2 & 2 & 1.6 & 773 & 25.01 & 2.50 & 1.07 & 2.86 \\
\hline F-10 & Mudstone & 2 & 2 & 1 & 1.5 & 864 & 12.10 & 0.91 & 0.60 & 1.36 \\
\hline
\end{tabular}

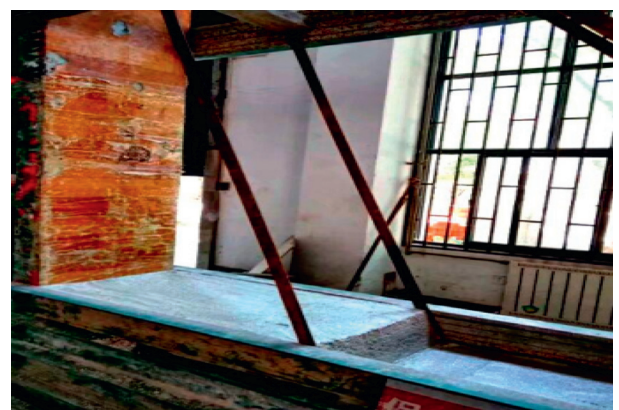

FIGURE 2: Layout of the steel strip.

At this point in time, the hanging wall of the fault is considered to have been activated. The fault destroys the integrity of the rock mass such that compared with the structure of the arch overburden, which is not affected by the fault, the arch overburden shows singularity, and the development of the arch is discontinuous.

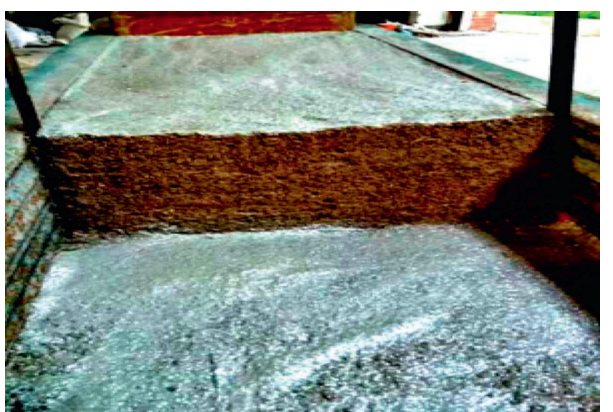

Figure 3: Layout of the test model.

As Figure 7 shows, when the panel is mined $20 \mathrm{~m}$ away from the fault, the movement of the overburden strata is significantly affected by the fault, the degree of overburden damage is further increased, horizontal transverse fractures have a significant effect on the fault, and the fractures are 


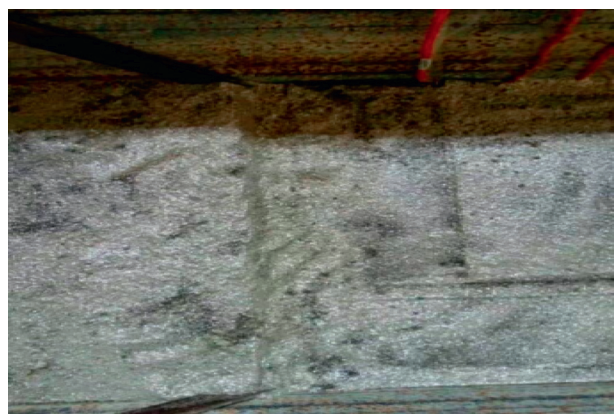

FIGURE 4: Layout of the fault zone.

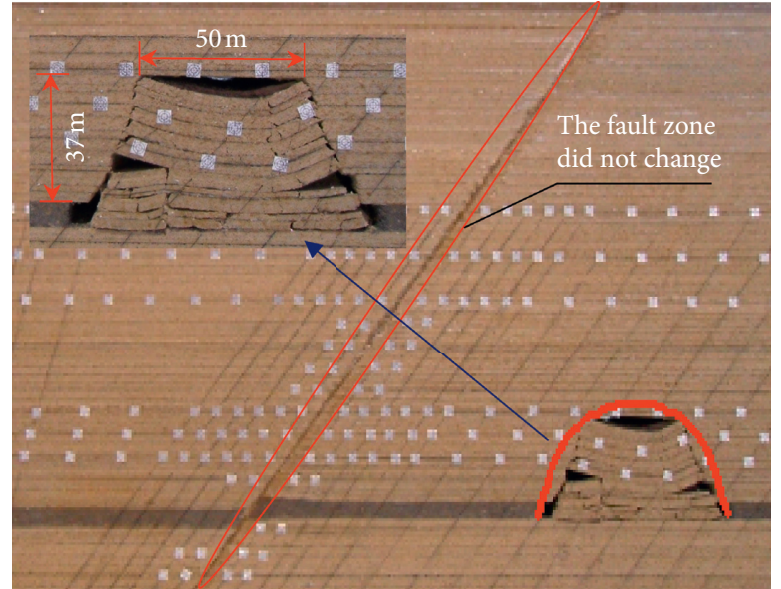

(a)

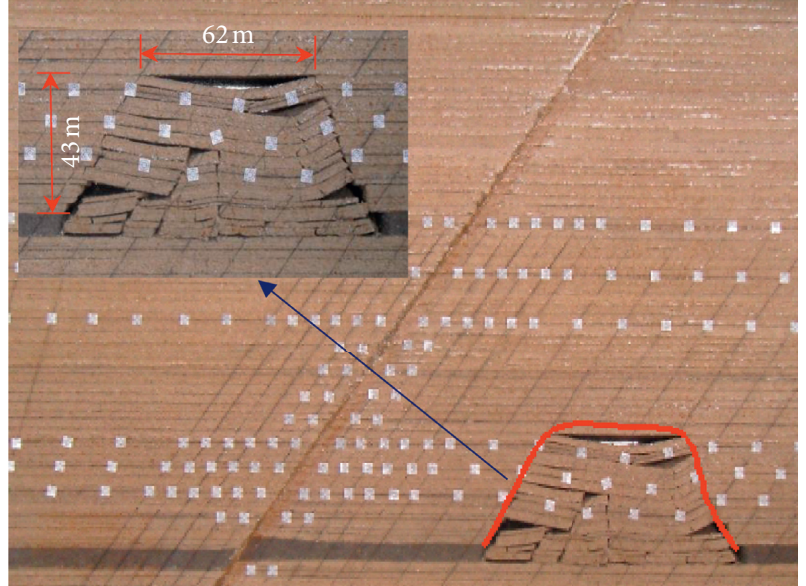

(b)

Figure 5: Overburden structure when the working face is $140 \mathrm{~m}$ or $110 \mathrm{~m}$ away from the fault. (a) Distance from the fault, $140 \mathrm{~m}$ (90 $\mathrm{m}$ mined). (b) Distance from the fault, $110 \mathrm{~m}$.

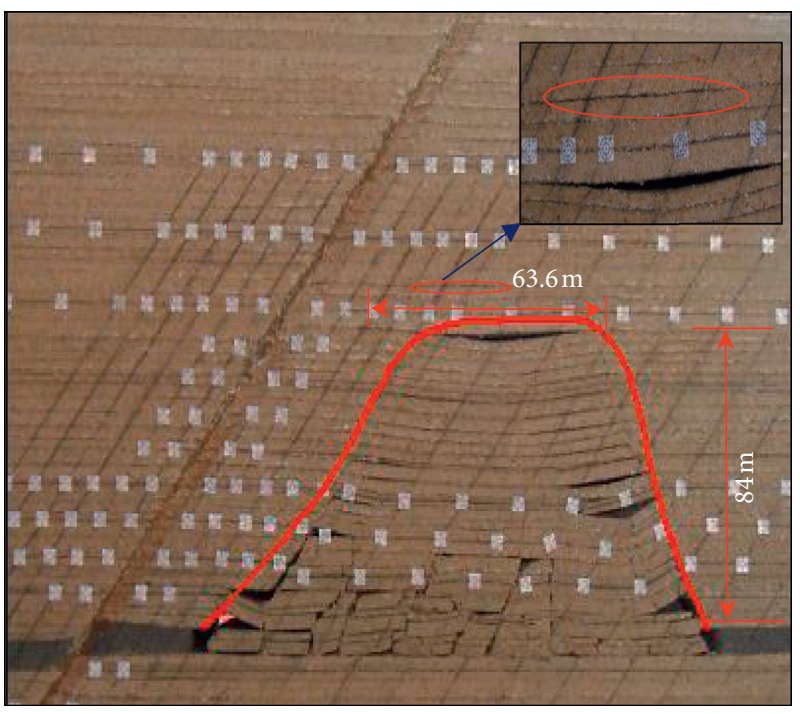

(a)

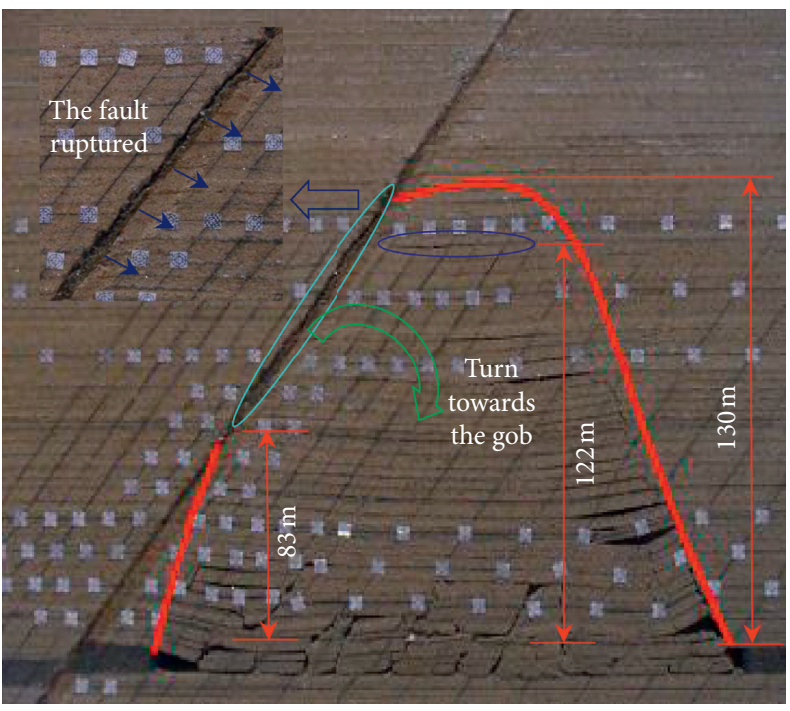

(b)

FIGURE 6: Overburden structure when the working face is $40 \mathrm{~m}$ or $30 \mathrm{~m}$ away from the fault. (a) Distance from the fault, $40 \mathrm{~m}$. (b) Distance from the fault, $30 \mathrm{~m}$. 


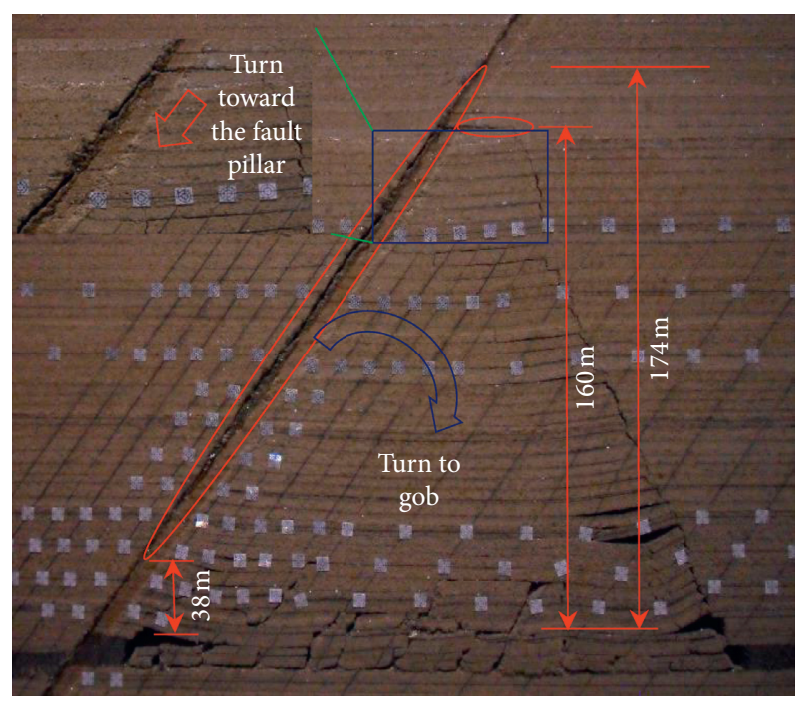

(a)

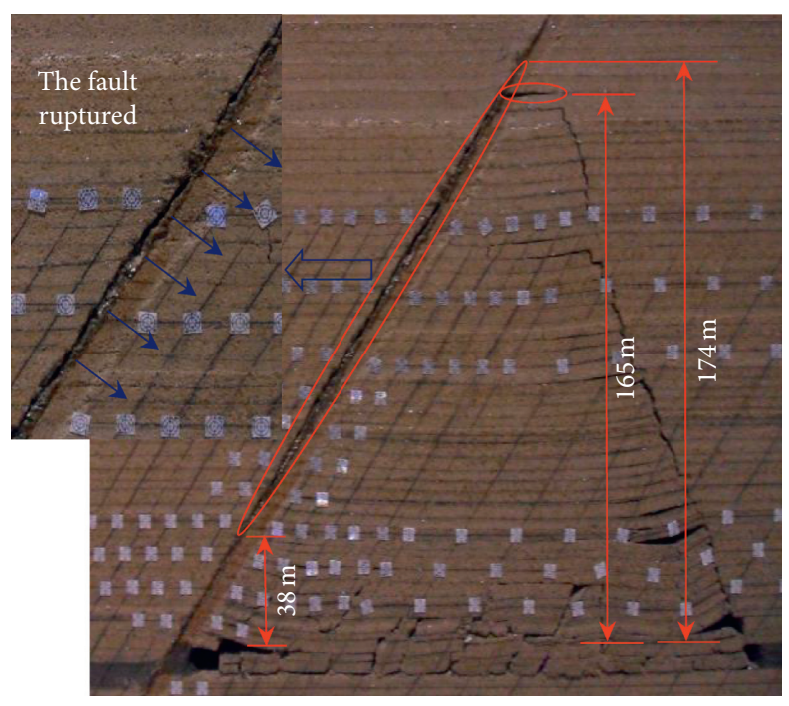

(b)

Figure 7: Overburden structure when the working face is $20 \mathrm{~m}$ or $10 \mathrm{~m}$ away from the fault. (a) Distance from the fault, $20 \mathrm{~m}$. (b) Distance from the fault, $10 \mathrm{~m}$.

connected with the fault. The upper overburden turns in the direction of the pillar around the fault, and the lower strata are under pressure, which causes the overburden to continue to turn into the goaf. As a result, the activation range of the fault increases, the fracture range of the fault increases, the maximum height of the fracture range of the fault zone is $174 \mathrm{~m}$ above the coal seam, and the minimum height is $38 \mathrm{~m}$ above the coal seam. When the working face is $10 \mathrm{~m}$ away from the fault, the footwall rock mass continues to turn towards the goaf under the influence of mining. The fracture range of the fault basically does not increase, although the fracture expansion width increases. The working face is within $20 \mathrm{~m}$ and $10 \mathrm{~m}$ away from the fault, the arch overburden structure is seriously damaged, and the arch structure basically disappears.

As shown in Figure 8, when the working face is mined to the fault, the footwall overburden loses the support of the coal, the footwall strata are cut off, and the relative displacement of the two walls is obviously staggered, which may cause a strong rock burst in the panel. Transverse fractures are blocked by faults and stop developing. The high position of the footwall rock mass is cut off, and the high position of the hanging wall rock mass sinks, resulting in the closure of the fault fractures. However, the footwall rock mass near the coal seam continues to turn towards the goaf, and the activation degree of the fault near the coal seam intensifies. When the working face advances to the fault, the highposition rock mass as a whole is cut off, and the rock mass near the coal seam rotation has a strong impact on the panel. Thus, during working face mining, it is necessary to strengthen the support and take measures to prevent the occurrence of a rock burst disaster.

In summary, when the working face of the footwall is far away from the fault, the overburden structure is not affected by the fault. When the working face of the footwall is $30 \mathrm{~m}$ away from the fault, the arch structure is damaged, the high position of the fault is activated first, and obvious dislocation occurs between the two walls. When the panel is mined to the fault, the transverse fractures are connected to the fault zone, and the footwall overburden loses the support of the coal body, which results in overall shear off. The degree of fault activation is high, and the working face is prone to dynamic disasters. When the working face is within $0-30 \mathrm{~m}$ away from the fault, preventive measures should be taken to avoid a rock burst caused by fault activation.

\section{Establishment of a Numerical Model and Monitoring Scheme}

FLAC3D was used to establish the calculation model. The size of the model is $509 \mathrm{~m}$ (length) $\times 300 \mathrm{~m}$ (width) $\times 150 \mathrm{~m}$ (height), and the buried depth of the simulated coal seam is $630 \mathrm{~m}$. The thickness of the coal seam, the drop, and the angle of the fault are the same as those in similar simulation tests. The model is shown in Figure 9 [15]. A uniform load of $14 \mathrm{MPa}$ is applied to the top of the model to simulate the load on the rock formation above the model. The trapezoidal distributed load is applied in the horizontal direction. According to the in situ stress monitoring results, the horizontal stress is 0.8 times the vertical stress. The front and rear boundaries limit the displacement in the $y$-direction, the bottom boundary limits the displacement in the $z$-direction, and the remaining boundary is set as a free surface [35]. The fault is simulated with a soft rock mass with a width of $1 \mathrm{~m}$ [13], and the interfaces are embedded on both sides of the fault zone [34]. The fault and rock mechanic parameters are shown in Table 3.

To study the evolution law of the stress, the roof movement characteristics, and fault activation rule when the working face advanced towards the fault direction, the monitoring points and the monitoring lines were set, as shown in Figure 10 [15]. The monitoring points $A$ and $A^{\prime}$ 


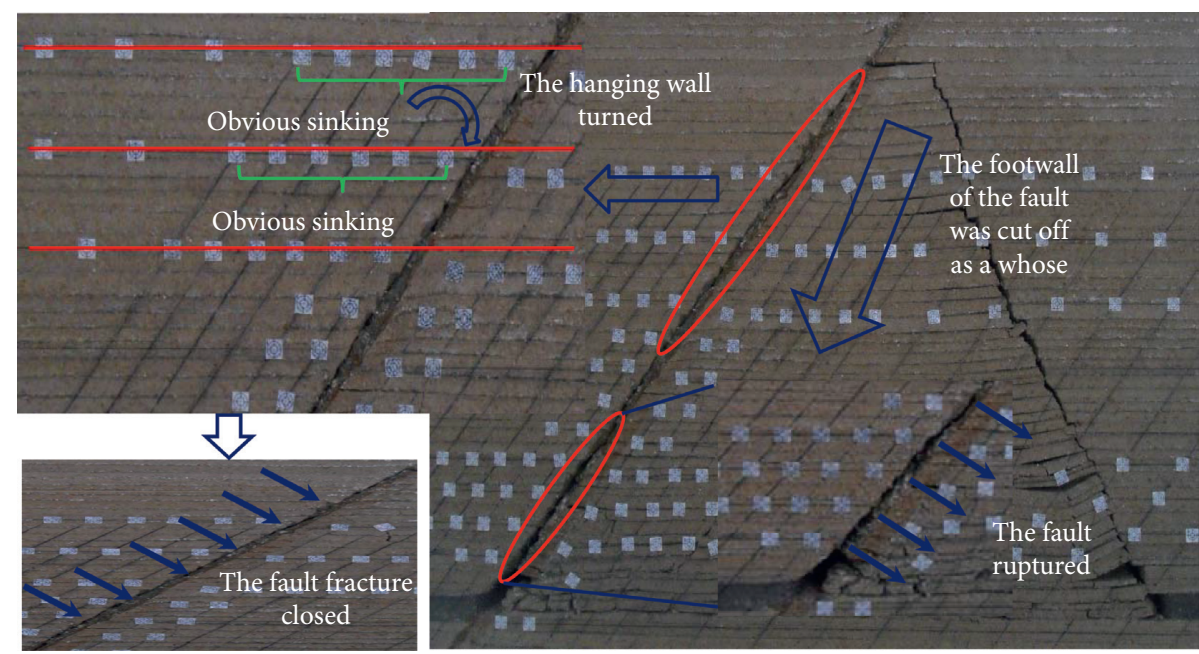

Figure 8: Overburden structure when the panel is mined to the fault.

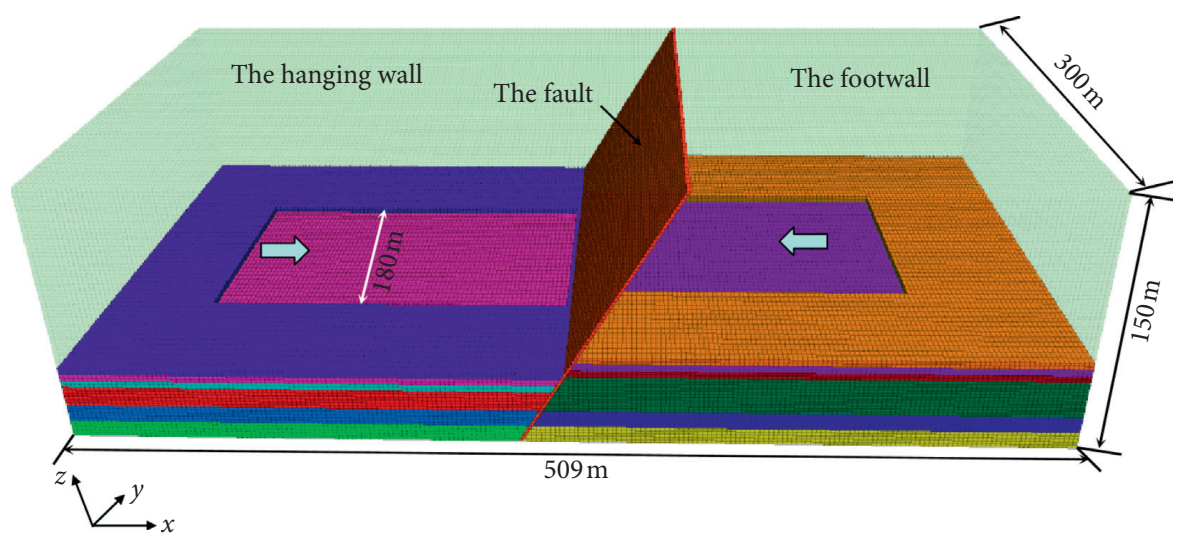

Figure 9: Schematic diagram of the three-dimensional numerical model.

TABLE 3: Model strata and mechanical parameters.

\begin{tabular}{|c|c|c|c|c|c|c|}
\hline Lithology & Density $\left(\mathrm{kg} / \mathrm{m}^{3}\right)$ & Bulk modulus (GPa) & Shear modulus (GPa) & Cohesion (MPa) & Tensile strength $(\mathrm{MPa})$ & Friction angle $\left({ }^{\circ}\right)$ \\
\hline Gritstone & 2400 & 8.2 & 7.5 & 1.2 & 3.96 & 41 \\
\hline Siltstone & 2530 & 13.4 & 7.6 & 1.4 & 1.85 & 37 \\
\hline Coal & 1350 & 10.5 & 6.5 & 1.2 & 0.5 & 23 \\
\hline Packsand & 2530 & 13.4 & 7.6 & 1.4 & 4.0 & 37 \\
\hline Mudstone & 2340 & 9.8 & 7.1 & 0.5 & 3.0 & 39 \\
\hline Fault & 2000 & 0.01 & 0.0035 & 0.001 & 0.2 & 5 \\
\hline
\end{tabular}

and $B$ and $B^{\prime}$ are located $10 \mathrm{~m}$ and $70 \mathrm{~m}$ away from the coal seam, respectively.

\section{Analysis of the Numerical Simulation Results}

5.1. Evolution Law of Mining-Induced Stress on the Working Face. When the footwall panel is mined towards the fault direction, the vertical stress distribution of the surrounding rock is in the middle of the working face and the coal seam plane is at different distances from the fault, as shown in Figure 11. When the footwall working face is far away from the fault, the fault has no influence on the surrounding rock stress distribution of the working face, and when the working face is near the fault, the fault has a significant barrier effect on the stress distribution. As shown in Figures 11(a)-11(e), when the working face approaches the fault, the cutting effect of the fault is obvious. The stress barrier effect of the fault zone is more prominent, thus preventing the transmission of mining-induced stress, and the stress concentration degree in front of the coal wall gradually increases. Moreover, the stress concentration degree near the footer fault gradually increases, as does the stress concentration degree range between the fault and the coal wall; the rock burst potential increases as well. For the 


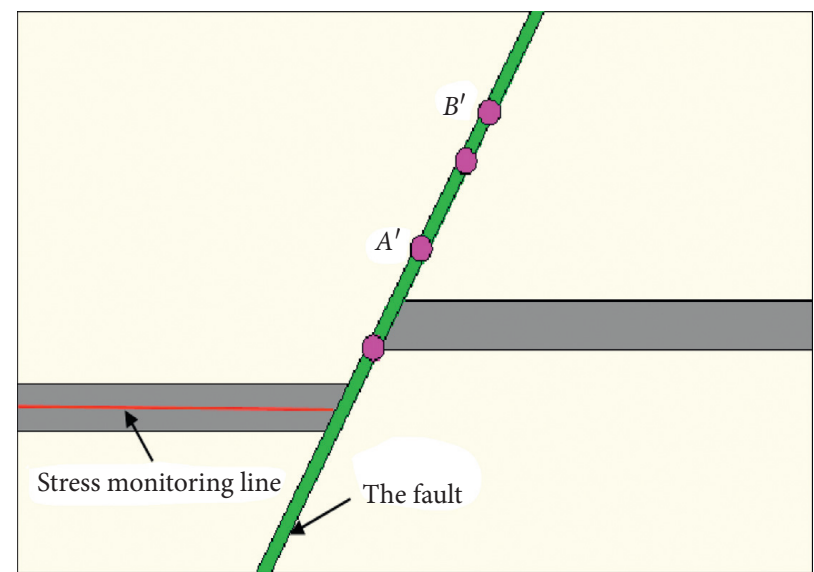

Figure 10: Schematic diagram of the numerical simulation monitoring point layout.

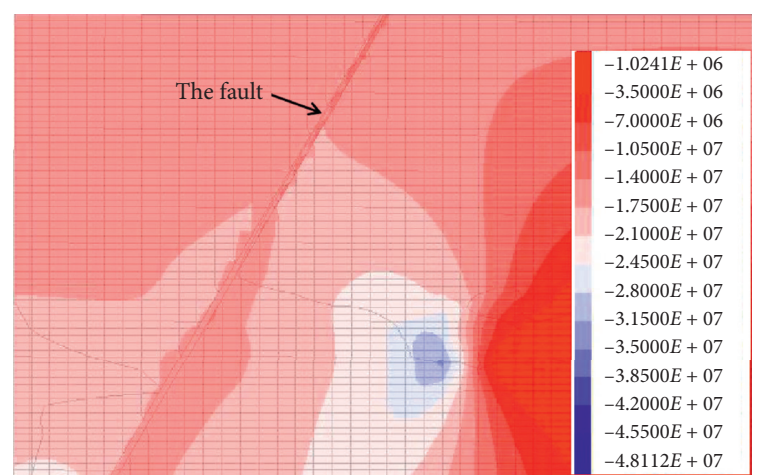

(i)

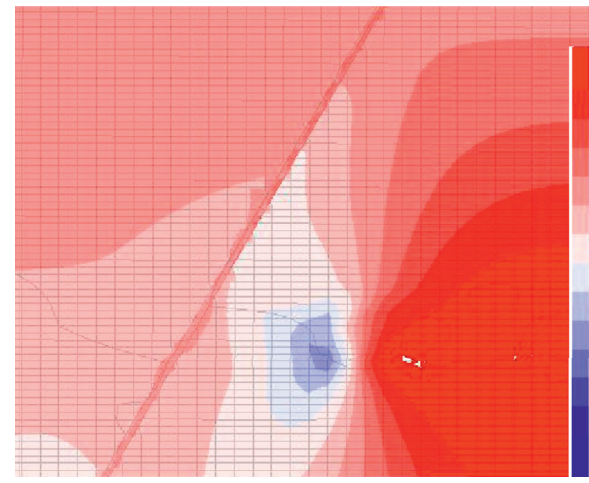

(i)

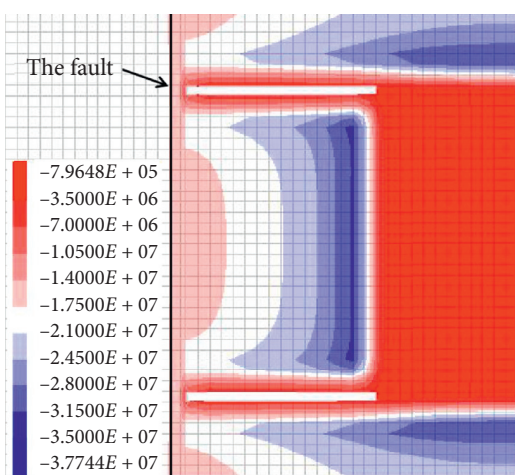

(ii)

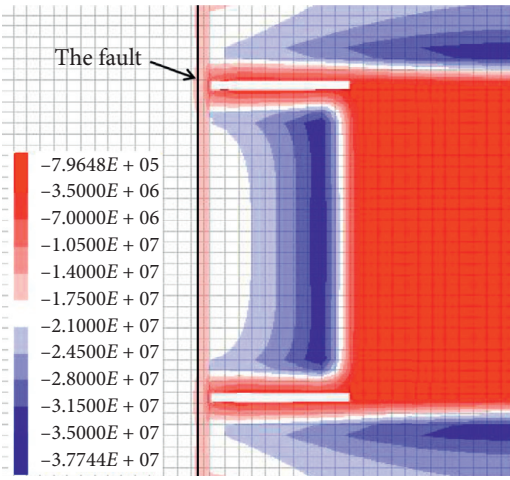

(ii)

(b)

Figure 11: Continued. 


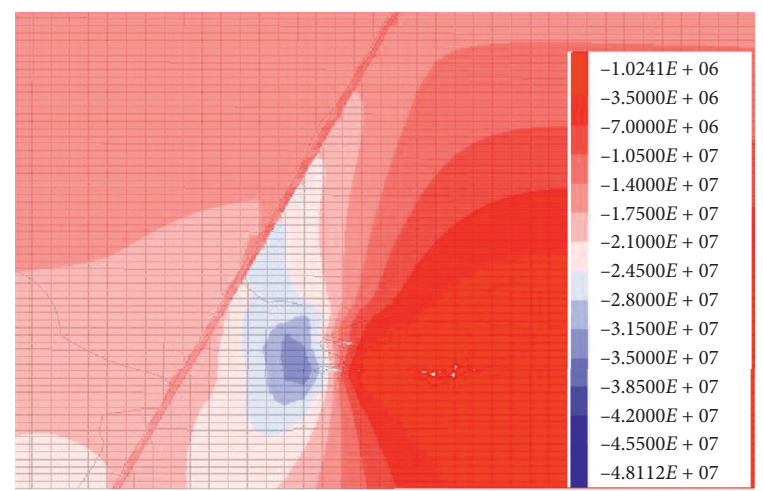

(i)

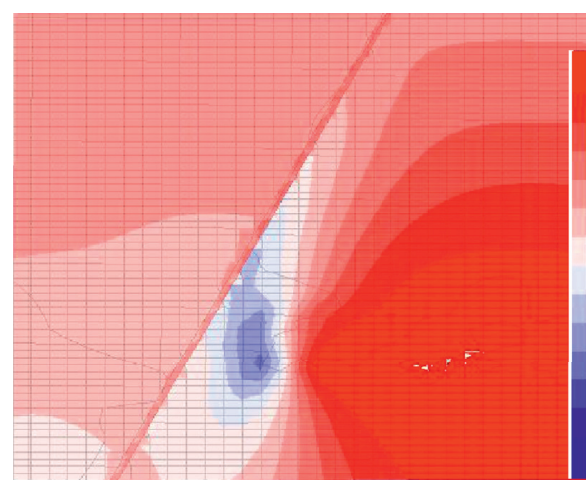

(i)

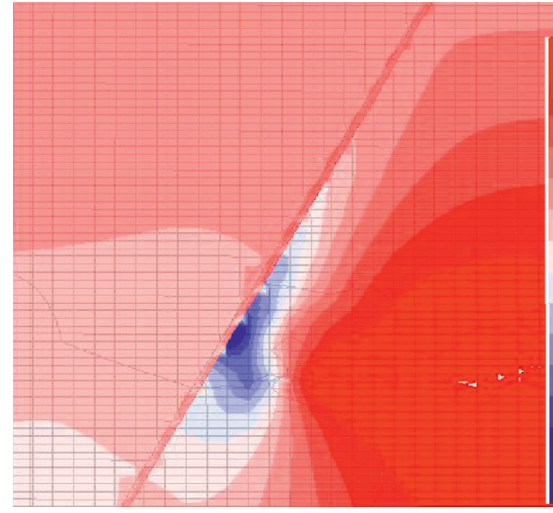

(i)

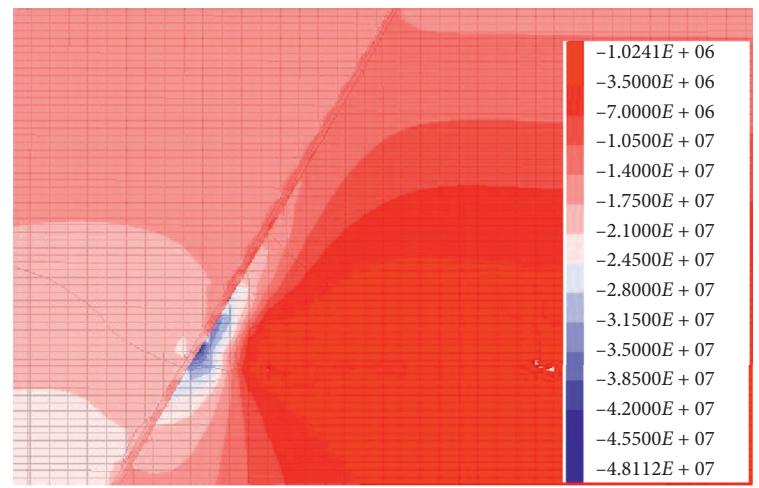

(i)

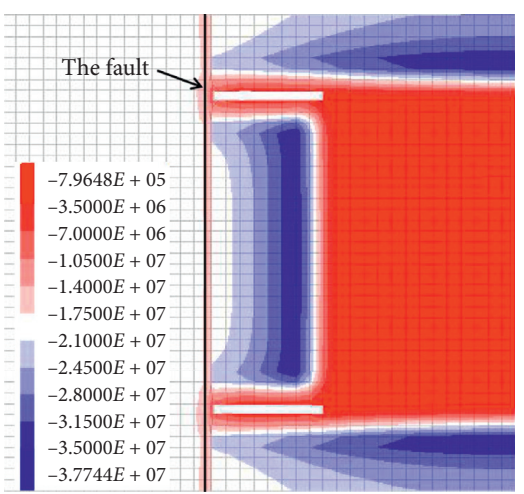

(ii)

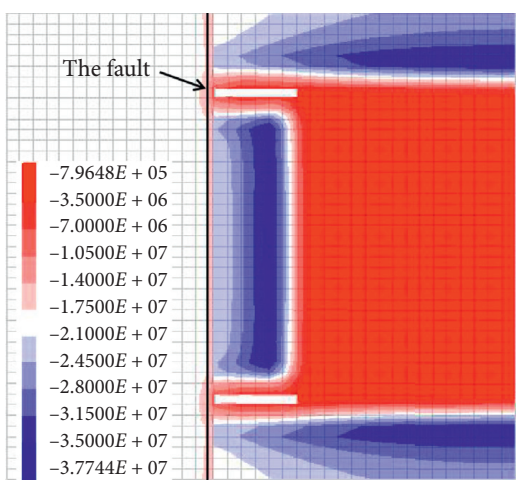

(ii)

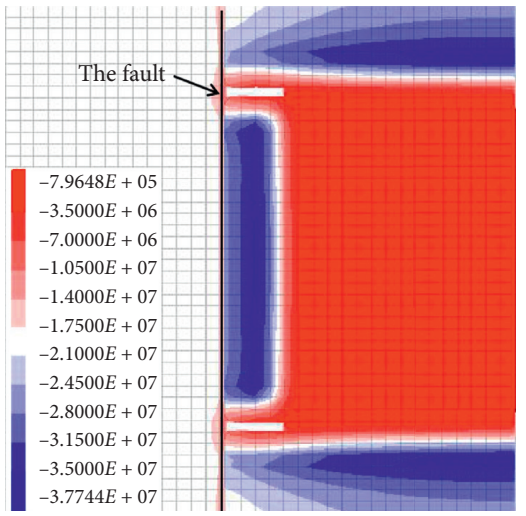

(ii)

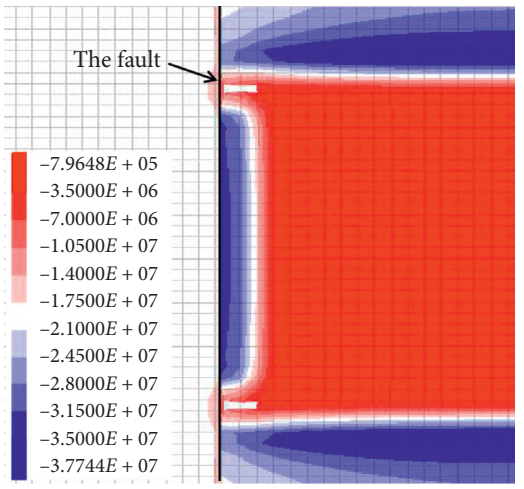

(ii)

(f)

Figure 11: Continued. 


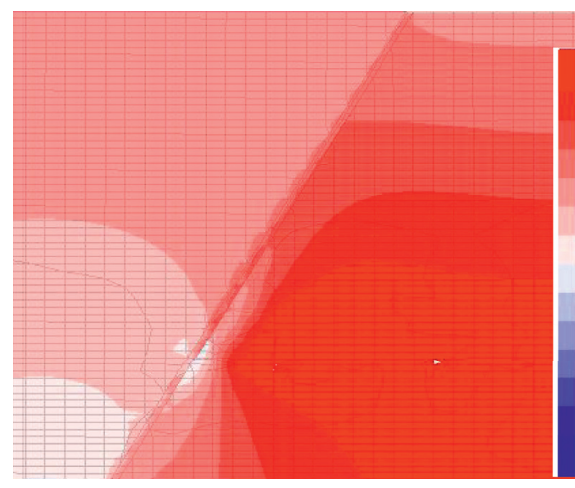

(i)

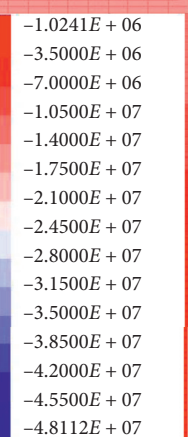

$-4.8112 E+07$

(g)

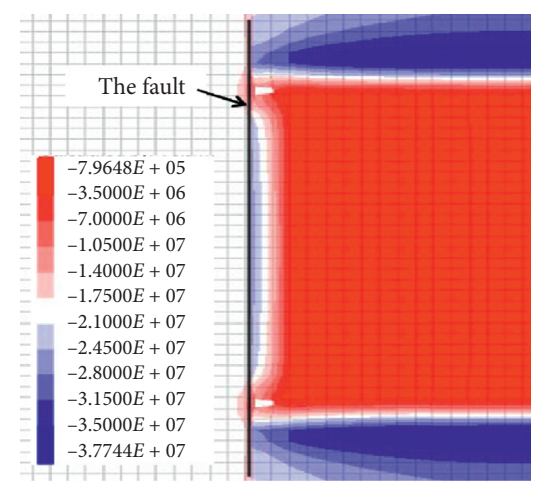

(ii)

FIGURE 11: Distribution of the vertical stress at different spacings between the mining face and fault in the footwall. (a) When the working face is $80 \mathrm{~m}$ away from the fault. (i) Strike at the middle of the working face. (ii) Horizontal direction of the coal seam. (b) When the working face is $50 \mathrm{~m}$ away from the fault. (i) Strike at the middle of the working face. (ii) Horizontal direction of the coal seam. (c) When the working face is $40 \mathrm{~m}$ away from the fault. (i) Strike at the middle of the working face. (ii) Horizontal direction of the coal seam. (d) When the working face is $30 \mathrm{~m}$ away from the fault. (i) Strike at the middle of the working face. (ii) Horizontal direction of the coal seam. (e) When the working face is $20 \mathrm{~m}$ away from the fault. (i) Strike at the middle of the working face. (ii) Horizontal direction of the coal seam. (f) When the working face is $10 \mathrm{~m}$ away from the fault. (i) Strike at the middle of the working face. (ii) Horizontal direction of the coal seam. (g) When the working face is $5 \mathrm{~m}$ away from the fault. (i) Strike at the middle of the working face. (ii) Horizontal direction of the coal seam.

footwall panel mining, the overburden structure obtained from similar simulation tests shows that the high position of the fault zone is activated first, and it is opened and miscarried. The overburden turns and sinks towards the goaf, and a high stress concentration is formed above the coal pillar near the fault. The results of similar simulation and numerical simulation tests are mutually verified, which proves that the experimental results are reasonable. When the width of the coal pillar is $20 \mathrm{~m}$ and $40 \mathrm{~m}$, the coal pillar has a strong bearing capacity and can bear a rock load above the coal pillar well. The overburden structure is wedgeshaped with poor stability, and the coal pillar near the fault bears much of the static load and the dynamic load generated by the fault slip. In addition, the overburden wedge-shaped structure leads to an obvious stress concentration in the lower roof, which is near the coal seam and leads to dynamic disasters such as rock bursts. When the working face is mined in this area, preventive measures should be taken to prevent the occurrence of dynamic disasters such as rock bursts. When the distance between the working face and the fault continues to decrease, plastic failure occurs in the coal pillar, and the stress will be released and transferred. The stress concentration degree in front of the working face will decrease, as shown in Figures 11(f) and 11(g).

The stress distribution characteristics of the abutment stress ahead of the working face under different distances between the working face and the fault are shown in Figure 12 . When the distance between the working face and the fault decreases from $100 \mathrm{~m}$ to $20 \mathrm{~m}$ due to the cutting action of the fault, the stress concentration in front of working face increases and the peak value of abutment stress in front of the working face gradually increases from $32 \mathrm{MPa}$ to 39.5 MPa. When the distance between the working face and the fault decreases from $20 \mathrm{~m}$ to $10 \mathrm{~m}$, the coal pillar is partially unstable, and the bearing capacity decreases, which

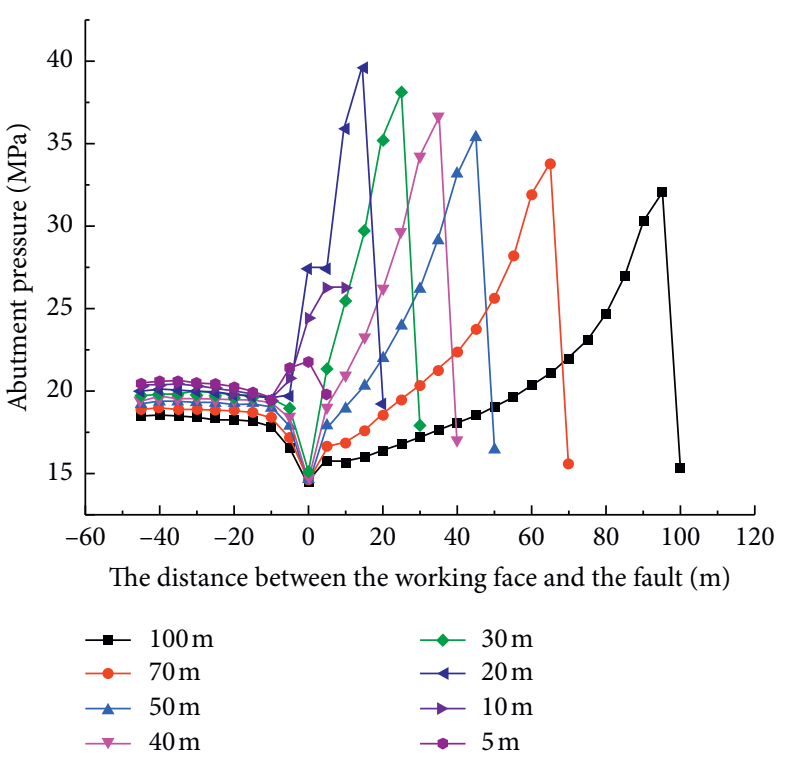

FIGURE 12: Distribution characteristics of the abutment pressure in footwall face fault mining.

leads to a gradual decrease in the peak value of the abutment stress in front of the working face to $26 \mathrm{MPa}$. When the working face is $5 \mathrm{~m}$ away from the fault, the bearing capacity of the coal pillar is reduced further, and the peak stress is only $16.8 \mathrm{MPa}$.

As shown in Figures 11 and 12, under the influence of the fault, when the coal pillar between the footwall working face and the fault is in a stable state, the peak stress in front of the working face increases gradually, as does the rock burst potential on the working face. When the distance between 
the working face and the fault is larger than $10 \mathrm{~m}$, plastic damage occurs in parts of the coal pillar, but the coal pillar is still in a state of high stress, causing the rock burst potential of the working face to increase further. When the width of the coal pillar is less than or equal to $10 \mathrm{~m}$, the coal pillar is completely in the yield state, and the abutment stress of the coal pillar is significantly reduced. Therefore, as the distance between the footwall working face and the fault decreases, the monitoring and early warning of rock bursts should be strengthened. Pressure relief measures should be taken, and roof support should be strengthened, especially in the area $10-30 \mathrm{~m}$ away from the fault.

\subsection{Stress Evolution Characteristics of the Fault Plane.} Figure 13 and Table 4 show that the stress variation characteristics of the fault zone have obvious spatial effects and that the stress variation characteristics of point $A^{\prime}$ and point $B^{\prime}$ are completely different. The normal stress at point $B^{\prime}$ of the upper fault plane decreases gradually when the working face is within $100 \mathrm{~m}$ away from the fault, and the fault plane is in a state of stress relaxation. When the working face is $10 \mathrm{~m}$ away from the fault, the normal stress decreases rapidly to $7.5 \mathrm{MPa}$, which is much lower than the original rock stress. At this time, tensile failure occurs in the fault at high positions. Figure 13(a) shows that the normal stress at measuring point $A^{\prime}$ exhibits an upward trend when the distance between the working face and the fault decreases from $100 \mathrm{~m}$ to $40 \mathrm{~m}$, and the normal stress increases from 14.1 MPa to 16.4 MPa. The normal stress decreases when the distance between the working face and the fault decreases from $40 \mathrm{~m}$ to $20 \mathrm{~m}$, although the normal stress is still higher than the original normal stress of the fault. When the working face is $10 \mathrm{~m}$ away from the fault, the normal stress decreases rapidly to $10.5 \mathrm{MPa}$. When the working face is $5 \mathrm{~m}$ away from the fault, the normal stress continues to decrease to $6.5 \mathrm{MPa}$, which is far lower than the original normal stress of the fault. The shear stress variation rule at point $A^{\prime}$ presents a fluctuating change, decreasing to a minimum value of $0.13 \mathrm{MPa}$ within $100-30 \mathrm{~m}$ away from the fault and reaching a maximum value of $1.65 \mathrm{MPa}$ at $20 \mathrm{~m}$ away from the fault, and then the shear stress decreases. As Figure 13(b) shows, the variation in the shear stress of the fault is different from the variation in normal stress. The shear stress at point $B^{\prime}$ decreases when the distance between the working face and the fault decreases from $100 \mathrm{~m}$ to $60 \mathrm{~m}$, and the stress is much lower than the original shear stress of the fault. The shear stress increases when the distance between the working face and the fault decreases from $60 \mathrm{~m}$ to $5 \mathrm{~m}$ and reaches the peak value of $4 \mathrm{MPa}$ at $5 \mathrm{~m}$.

5.3. Risk Analysis of Fault Activation. As Figure 14 shows, for point $A^{\prime}$, when the distance between the working face and the fault is more than $30 \mathrm{~m}$, the relative subsidence of the two walls of the fault is small. Within the range of $90-30 \mathrm{~m}$, the relative subsidence increases slightly, and the fault is in a stable state. When the distance between the working face and the fault decreases to $20 \mathrm{~m}$, the relative subsidence of the two walls significantly increases. At this time, the fault is activated and is in a dangerous state. Similarly, for point $B^{\prime}$, when the distance between the working face and the fault is more than $50 \mathrm{~m}$, the relative subsidence of the two walls is small, and when it is less than $50 \mathrm{~m}$, the relative subsidence increases sharply.

Figure 15 and Table 4 show that the ratio of shear stress to normal stress is different between points $A^{\prime}$ and $B^{\prime}$. When the distance between the working face and the fault decreases from $100 \mathrm{~m}$ to $30 \mathrm{~m}$, the shear stress at point $A^{\prime}$ shows a decreasing trend, the normal stress shows an increasing trend, and the ratio of shear stress to normal stress shows a decreasing trend, indicating that the shear stress at point $A^{\prime}$ decreases less than the normal stress. When the distance between the working face and the fault decreases from $30 \mathrm{~m}$ to $20 \mathrm{~m}$, the ratio of shear stress to normal stress at point $A^{\prime}$ increases from 0.008 to 0.123 . As Figure 16 shows, when the working face is $20 \mathrm{~m}$ away from the fault, the shear stress increases rapidly, and the normal stress shows a decreasing trend, which indicates that shear stress is more sensitive to fault activation than normal stress. At this time, the fault is more likely to be activated. When the working face is $10 \mathrm{~m}$ away from the fault, the ratio of shear stress to normal stress at point $A^{\prime}$ decreases, the fault plane opens and relaxes, and the normal stress and shear stress both decrease. Combined with the relative subsidence of the two walls, the fault is fully activated at this time.

For measuring point $B^{\prime}$, when the distance between the working face and the fault is greater than $60 \mathrm{~m}$, the ratio of shear stress to normal stress changes slightly, and the fault zone is relatively stable. When the working face is mined $50 \mathrm{~m}$ from the fault, the increase in the amplitude of shear stress is larger than the decrease in the amplitude of normal stress, resulting in an increase in the ratio of shear stress to normal stress to 0.718 . When the distance between the working face and the fault is $40 \mathrm{~m}$, the ratio of shear stress to normal stress starts to decrease sharply. Combined with the relative subsidence of the two walls, the fault is activated. Fault activation occurs earlier at point $B^{\prime}$ than at point $A^{\prime}$.

Therefore, in footwall panel mining, activation of the fault in the high position should precede activation of the fault in the lower position near the coal seam. The increase in shear stress and decrease in normal stress caused by mining disturbances can both lead to the possibility of fault activation. In footwall panel mining, when the working face is $50 \mathrm{~m}$ and $20 \mathrm{~m}$ away from the fault, the faults in the high position and in the lower position are most likely to be activated.

\section{Relationship among Disturbance, Overburden Movement, Mining Stress, and Induced Dynamic Disasters}

The relationship among overburden movement, the stress evolution of the fault zone, and induced dynamic disasters can be obtained by analyzing the distribution rule of mininginduced stress and the fault activation rule during the period of mining the panel through the fault. 


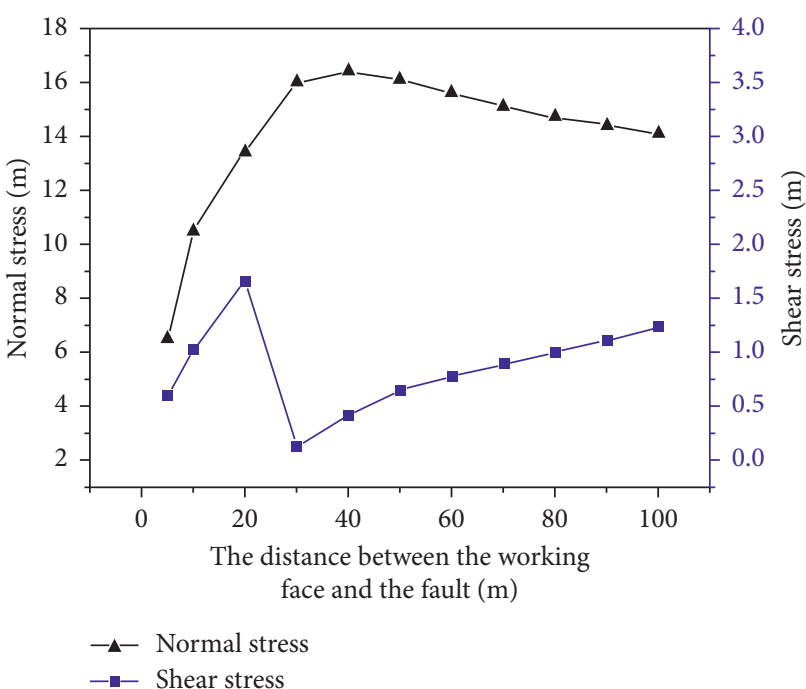

(a)

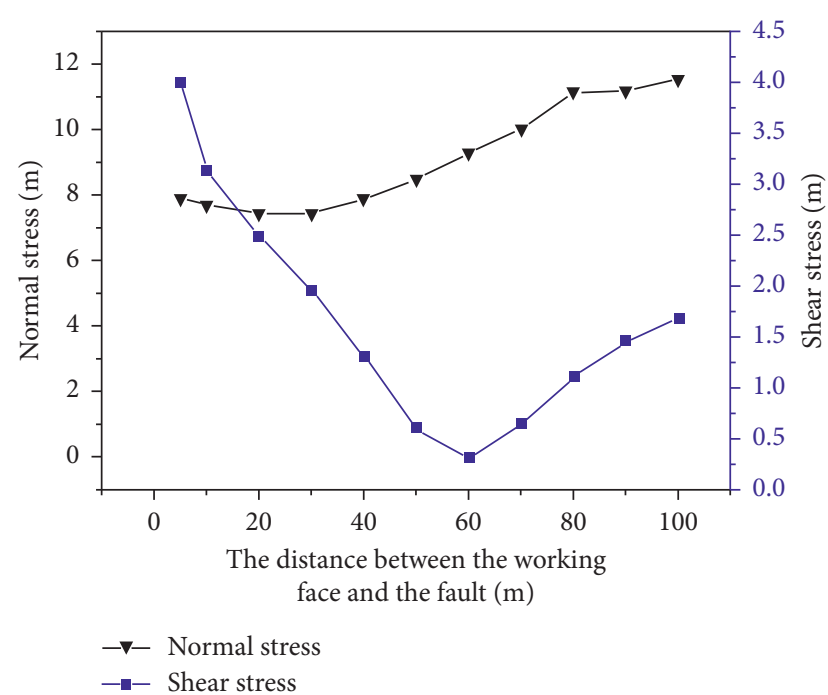

(b)

Figure 13: Stress variation in the fault plane in footwall mining. (a) Point $A^{\prime}$. (b) Point $B^{\prime}$.

TABLE 4: Data on stress variation in the fault plane at different distances between the working face and the fault in footwall mining.

\begin{tabular}{|c|c|c|c|c|c|c|}
\hline \multirow{2}{*}{ Distance from the fault $(\mathrm{m})$} & \multicolumn{3}{|c|}{ Point $A^{\prime}$} & \multicolumn{3}{|c|}{ Point $B^{\prime}$} \\
\hline & Shear $\tau(\mathrm{MPa})$ & Normal $\sigma(\mathrm{MPa})$ & $\tau / \sigma$ & Shear $\tau(\mathrm{MPa})$ & Normal $\sigma(\mathrm{MPa})$ & $\tau / \sigma$ \\
\hline 100 & 1.24 & 14.1 & 0.0879 & 1.69 & 11.54 & 0.146 \\
\hline 90 & 1.11 & 14.4 & 0.077 & 1.46 & 11.19 & 0.13 \\
\hline 80 & 1 & 14.7 & 0.068 & 1.12 & 11.15 & 0.1 \\
\hline 70 & 0.89 & 15.1 & 0.059 & 0.65 & 10.04 & 0.065 \\
\hline 60 & 0.78 & 15.6 & 0.05 & 0.42 & 9.3 & 0.034 \\
\hline 50 & 0.65 & 16.1 & 0.04 & 0.61 & 8.5 & 0.718 \\
\hline 40 & 0.42 & 16.4 & 0.026 & 1.31 & 7.89 & 0.166 \\
\hline 30 & 0.13 & 16 & 0.008 & 1.96 & 7.45 & 0.263 \\
\hline 20 & 1.65 & 13.4 & 0.123 & 2.5 & 7.44 & 0.336 \\
\hline 10 & 1.02 & 10.5 & 0.097 & 3.14 & 7.71 & 0.407 \\
\hline 5 & 0.6 & 6.5 & 0.092 & 4 & 7.91 & 0.506 \\
\hline Original stress & 1.69 & 12.6 & & 1.55 & 12.4 & \\
\hline
\end{tabular}

As Figure 16 shows, the existence of the fault leads to a singularity of the stress distribution in the stope. When the working face is far away from the fault, mining disturbances have little influence on the fault. As the working face gets closer to the fault, the roof is broken, overburden movement affects the fault, and the stress environment of the fault zone changes to mainly the shear stress and normal stress. After the stress field of the fault zone changes, the surrounding rock system around the fault continuously accumulates energy. As the mining disturbance approaches the fault, the energy gradually accumulates before fault activation. When overburden movement caused by mining activities causes severe disturbances to the stress environment of the fault zone, the energy accumulated around the fault zone reaches a certain threshold, and the original balance system of the fault is broken. Under the action of the normal stress or shear stress of the fault zone, the fault system is activated, and a large amount of energy is released. The activation of the fault further intensifies the movement of the overburden, which further affects the stress of the fault and results in a wider range of fault activation. During slip and instability of the fault, along with a large release of energy, a rock burst disaster can be easily induced.

\section{Engineering Example Verification}

One side of Panel 6303 in the Jining No. 3 Coal Mine is the goaf of Panel 6302, and the other side is Panel 6304. The panel has a strike length of $2057.8 \mathrm{~m}$, and its length is $239.8 \mathrm{~m}$. The thickness of the coal seam is $2.8-6.8 \mathrm{~m}$, with an average thickness of $4.75 \mathrm{~m}$. The buried depth of the panel is $670-712 \mathrm{~m}$. The immediate roof is siltstone and siltstone interbedded, and it is dark gray, dense, and hard $(f=4-6)$. The main roof is medium sandstone, with a thickness of $7.83-27.45 \mathrm{~m}$ and an average thickness of $20.51 \mathrm{~m}$, and it is gray, dense and hard $(f=9-12)$. The bottom plate is siltstone, with a thickness of $0-3.2 \mathrm{~m}$, and it 


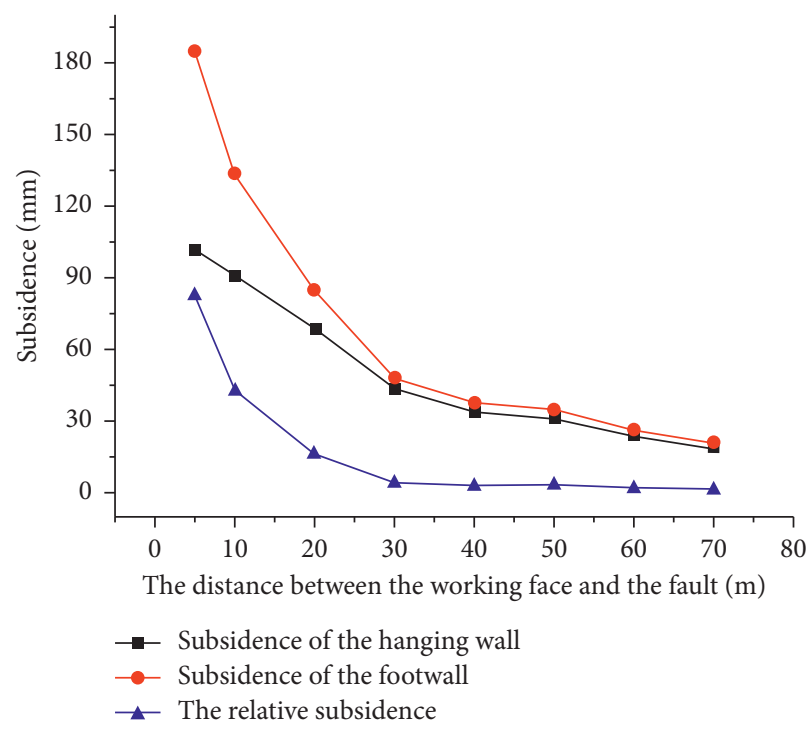

(a)

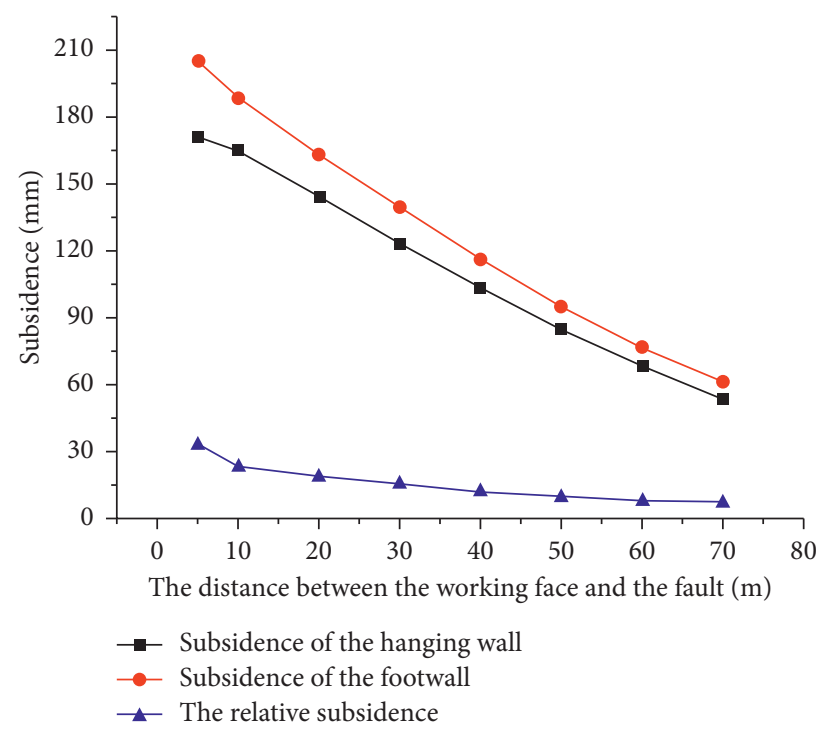

(b)

Figure 14: Two walls and the relative subsidence curves in footwall mining. (a) Point $A^{\prime}$. (b) Point $B^{\prime}$.

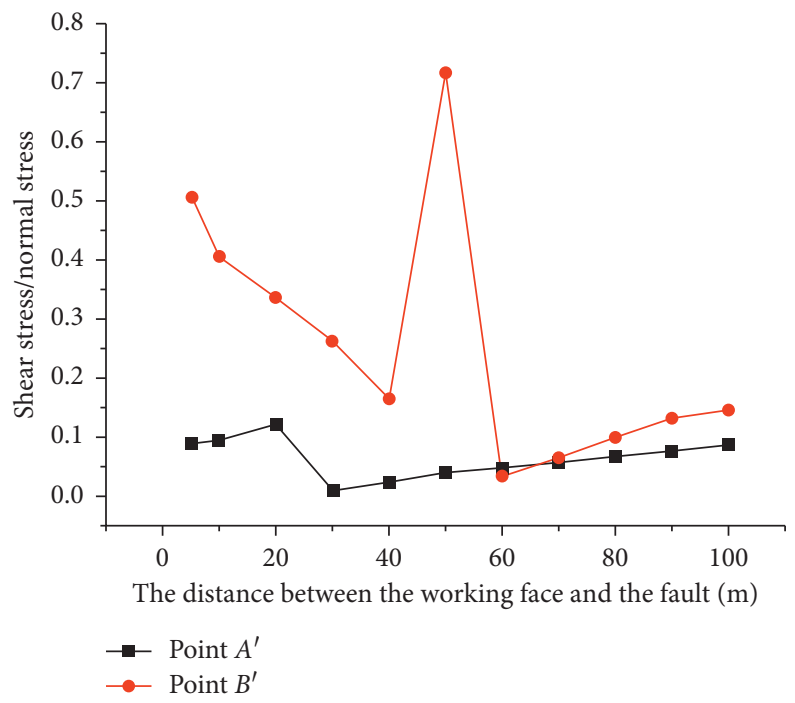

Figure 15: Ratio of shear stress to normal stress in footwall mining.

is light gray $(f=4-6)$. The working face advances towards the footwall of the SF28 fault, with a drop of $3 \mathrm{~m}$ and a dip angle of $47^{\circ}$.

When Panel 6303 was mined $35 \mathrm{~m}$ away from the SF28 fault, a serious rock burst accident occurred in the tailgate roadway of the hanging wall of the fault. The coal body on both sides of the tailgate roadway $66-96 \mathrm{~m}$ ahead of the working face suddenly protruded approximately $1.5-2.5 \mathrm{~m}$, and a slight vibration could be felt on the ground. When the working face was pushed to $20 \mathrm{~m}$ away from the SF28 fault, another rock burst accident occurred in the tailgate roadway approximately $12-36 \mathrm{~m}$ ahead of the working face. The two sides of the coal wall were deformed by approximately $300-500 \mathrm{~mm}, 8$ single pillars near the coal wall were flushed down, and the floor of the roadway bulged severely. The location of the rock burst occurred close to the footwall of the fault.

Panel 6303 of Jining No. 3 Coal Mine was mined through the fault from the footwall. Affected by mining, the fault was easily activated, and it released a large amount of energy and induced a rock burst on the working face. According to the results of the above similar simulation and numerical simulation research, within a range of $10-40 \mathrm{~m}$ in width, the coal pillar of the fault can bear a large amount of load. As a result, a large amount of energy can accumulate in the coal pillar. Moreover, mining activities can easily induce slippage of the fault to release a large amount of energy, causing a rock burst in the stope. The rationality and universality of the research results in this paper were verified by an example of a rock burst at the working face of 6303 as shown in Figure 17. 


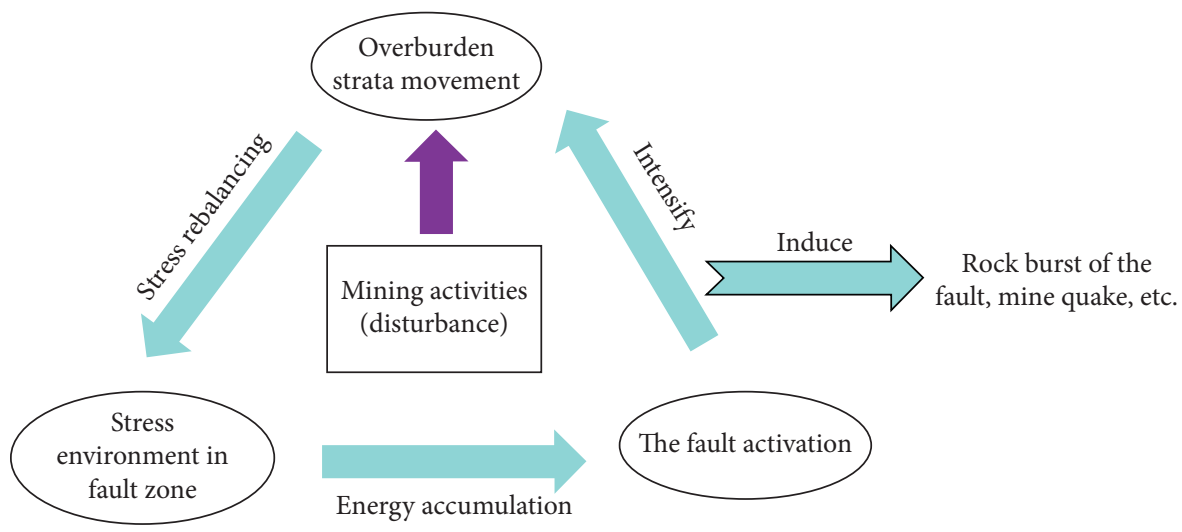

FIGURE 16: Relationship among overburden movement, the stress evolution of fault zone, and induced dynamic disasters.

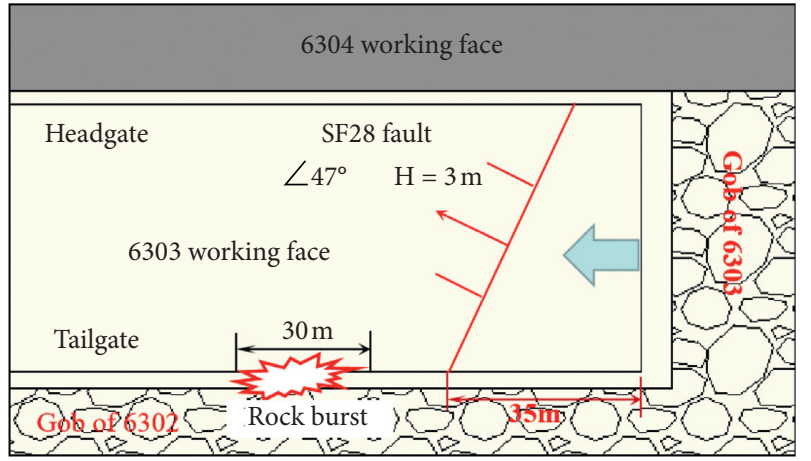

(a)

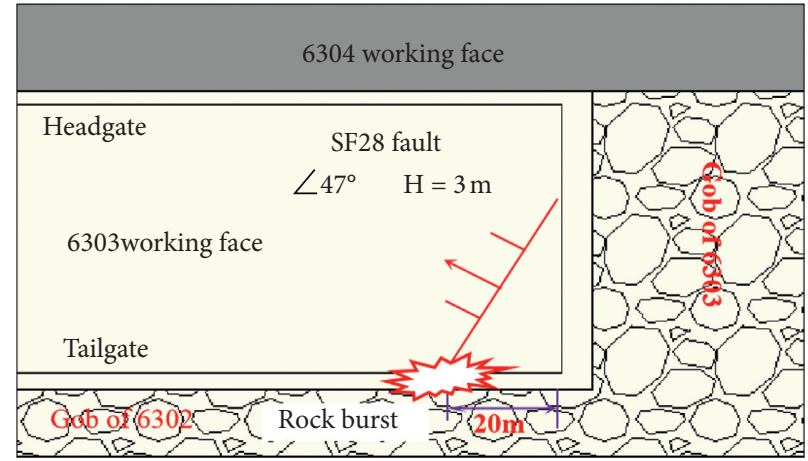

(b)

Figure 17: Location of a rock burst on an auxiliary roadway at 6303 in the Jining No. 3 Coal Mine. (a) The working face is $50 \mathrm{~m}$ away from the fault. (b) The working face is $50 \mathrm{~m}$ away from the fault.

\section{Conclusions}

In this paper, similarity simulation and numerical simulation models were established to study the evolution characteristics of the overburden structure and the evolutionary law of mining-induced stress in the process of footwall panel mining through a fault. Based on the results of these two models, the internal relationship among disturbance, overburden structure, mining stress, and an induced rock burst is proposed. We can draw several conclusions as follows:

(1) The overburden is arched. When the working face is $30 \mathrm{~m}$ away from the fault, the high position of the rock mass near the fault turns towards the goaf, leading to fault rupture. The high position of the fault is activated first, and the two walls are relatively obviously dislocated. As the panel is mined to the fault, the footwall overburden loses the support of the coal, the overburden as a whole is cut off, the degree of fault activation is high, and the working face is prone to dynamic disasters. When the working face is within $0-30 \mathrm{~m}$ of the fault, preventive measures should be taken to avoid rock bursts caused by fault slip.

(2) In the process of the footwall panel being mined through a fault, the abutment stress of the surrounding rock increases first and then decreases. When the working face is $20 \mathrm{~m}$ away from the fault, the abutment stress in the middle of the working face reaches the maximum. Within the range of 10-40 m in width, the coal pillar around the fault bears a large amount of load. As a result, a large amount of energy is accumulated in the coal pillar, which is very easy to activate and induce a rock burst.

(3) The ratio of shear stress to normal stress in the fault zone and the relative subsidence of the two walls were used as an index to judge the stability of the fault. During the mining process, an increase in shear stress or a decrease in normal stress can lead to a sharp increase in slippage and activation of the fault. When the footwall panel is mined, activation of the high position of the fault should precede activation of the lower position of the fault.

(4) Before fault activation, as the working surface approaches the fault, the energy that accumulated in the fault increases. When the accumulated energy reaches a certain threshold, the fault will be activated under the action of the normal stress or shear stress of the fault, and a large amount of energy will be released, which can easily induce dynamic disasters such as fault rock bursts or mine earthquakes. 
(5) Combined with the research results of similar simulation and numerical simulation models, this work reveals that during the process of mining the panel through the fault from the footwall, when the distance between the working face and the fault is less than or equal to $30 \mathrm{~m}$, monitoring, early warning and preventive measures should be taken to avoid rock bursts caused by fault activation.

\section{Data Availability}

The data used to support the findings of this study are included within the article.

\section{Conflicts of Interest}

The authors declare that there are no conflicts of interest related to the publication of this paper.

\section{Acknowledgments}

This research was funded by the Natural Science Foundation of Shandong Province (Grant no. ZR2018PEE007).

\section{References}

[1] L. Jiang, Q. Wu, Q. Wu et al., "Fracture failure analysis of hard and thick key layer and its dynamic response characteristics," Engineering Failure Analysis, vol. 98, pp. 118-130, 2019.

[2] Y. Yong, S. H. Tu, X. G. Zhang, and B. Li, "Dynamic effect and control of key strata break of immediate roof in fully mechanized mining with large mining height," Shock \& Vibration, vol. 201511 pages, Article ID 657818, 2015.

[3] Q. Wu, Q. Wu, Y. Xue, P. Kong, and B. Gong, "Analysis of overburden movement and disaster-causing effects of coal mining face under the action of hard thick magmatic rock," Processes, vol. 6, no. 9, p. 150, 2018.

[4] C. Lu, Y. Liu, H. Wang, and P. Liu, "Microseismic signals of double layer hard and thick igneous strata separation and fracturing," International Journal of Coal Geology, vol. 160161, pp. 28-41, 2016.

[5] L. S. Jiang, P. Kong, J. M. Shu et al., "Numerical analysis of support designs based on a case study of a longwall entry," Rock Mechanics and Rock Engineering, vol. 52, no. 9, pp. 3373-3384, 2019.

[6] Z. L. Li, L. M. Dou, W. Cai et al., "Investigation and analysis of the rock burst mechanism induced within fault-pillars," International Journal of Rock Mechanics and Mining Sciences, vol. 70, pp. 192-200, 2014.

[7] T. Li, Z. L. Mu, G. J. Liu, J. L. Du, and H. Lu, "Stress spatial evolution law and rockburst danger induced by coal mining in fault zone," International Journal of Mining Science and Technology, vol. 26, no. 3, pp. 409-415, 2016.

[8] W. Cai, L. M. Dou, Z. L. Li, J. He, H. He, and Y. L. Ding, "Mechanical initiation and propagation mechanism of a thrust fault: a case study of the Yima section of the XiashiYima thrust (north side of the eastern Qinling orogen, China)," Rock Mechanics and Rock Engineering, vol. 48, no. 5, pp. 1927-1945, 2015.

[9] Z. Lv, "Study on coal and rock instability mechanism and stability control under mining disturbance in fault areas," Dissertation, Xi'an University of Science and Technology, Xi'an, China, 2017.
[10] W. U. Quan-sen, L.-s. Jiang, and Q.-L. Wu, "Study on the law of mining stress evolution and fault activation under the influence of normal fault," Acta Geodynamica et Geomaterialia, vol. 187, no. 3, pp. 357-369, 2017.

[11] X. H. Chen, W. Q. Li, and X. Y. Yan, "Analysis on rock burst danger when fully-mechanized caving coal face passed fault with deep mining," Safety Science, vol. 50, no. 4, pp. 645-648, 2012.

[12] X.-S. Liu, J. Tan, Y.-L. Tan, Dou, and S.-C. Hu, "Pattern recognition of signals for the fault-slip type of rock burst in coal mines," Shock \& Vibration, vol. 2015, 8 pages, Article ID 806969, 2015.

[13] J. Jiang, Q. Wu, and H. Qu, "Evolution of mining stress and fault activation characteristics of thrust fault under hard and thick strata," Journal of Coal, vol. 40, no. 2, pp. 267$277,2015$.

[14] F. Jiang and J. Liu, "Analysis on control action of geologic structure on rock burst and typical cases," Journal of China Coal Society, vol. 37, no. 2, pp. 263-268, 2012, in Chinese.

[15] Q. Wu, Q. Wu, A. Yuan et al., "Analysis of mining effect and fault stability under the influence of normal faults," Geotechnical and Geological Engineering, 2020.

[16] P. Wang, L. S. Jiang, and P. Q. Zheng, "Application of equivalent materials to modeling fractures in the vicinity of a normal fault in the area of mining exploitation influence," Acta Geodynamica et Geomaterialia, vol. 14, pp. 475-485, 2017.

[17] J. B. Peng, L. W. Chen, Q. B. Huang, Y. M. Men, W. Fan, and J. K. Yan, "Physical simulation of ground fissures triggered by underground fault activity," Engineering Geology, vol. 155, pp. 19-30, 2013.

[18] Y. K. Liu, F. B. Zhou, L. Liu, C. Liu, and S. Y. Hu, "An experimental and numerical investigation on the deformation of overlying coal seams above double seam extraction for controlling coal mine methane emissions," International Journal of Coal Geology, vol. 87, pp. 139-149, 2011.

[19] A. Sainoki and H. S. Mitri, "Dynamic behaviour of mininginduced fault slip," International Journal of Rock Mechanics \& Mining Sciences, vol. 66, no. 1, pp. 19-29, 2014.

[20] A. Sainoki and H. S. Mitri, "Dynamic modelling of fault-slip with Barton's shear strength model," International Journal of Rock Mechanics and Mining Sciences, vol. 67, pp. 155-163, 2014.

[21] A. Sainoki and H. S. Mitri, "Effect of slip-weakening distance on selected seismic source parameters of mining-induced fault-slip," International Journal of Rock Mechanics and Mining Sciences, vol. 73, pp. 115-122, 2015.

[22] L. Jiang, P. Kong, and P. Zhang, "Dynamic analysis of the rock burst potential of a longwall panel intersecting with a fault," Rock Mechanics and Rock Engineering, vol. 53, no. 4, pp. 1737-1754, 2019.

[23] Z. L. Li, L. M. Dou, W. Cai et al., "Mechanical analysis of static stress within fault-pillars based on a voussoir beam structure," Rock Mechanics and Rock Engineering, vol. 49, no. 3, pp. 1097-1105, 2016.

[24] S. C. Zhang, W. J. Guo, Y. Y. Li, W. B. Sun, and D. W. Yin, "Experimental simulation of fault water inrush channel evolution in a coal mine floor," Mine Water and the Environment, vol. 36, no. 3, pp. 443-451, 2017.

[25] W. Müller, "Numerical simulation of rock bursts," Mining Science \& Technology, vol. 12, no. 1, pp. 27-42, 1991.

[26] J. W. Shi and Z. L. Chen, "Based on numerical simulation study of rockburst in roadway induced by fault," Advanced Materials Research, vol. 962-965, pp. 370-374, 2014. 
[27] G. Lafont, Y. Gunzburger, H. S. Mitri, M. Alheib, C. Didier, and J. P. Piguet, "Influence of mining excavation on energy redistribution and rockburst potential," in Proceedings of the World Mining Congress, Montreal, Canada, August 2013.

[28] Z. P. Meng, S. P. Peng, Y. Feng, and Z. Y. Lei, "Influence of fracture structure plane on underground pressure and roof stability of working face," Coal Geology \& Exploration, vol. 34, no. 3, pp. 24-27, 2006, in Chinese.

[29] A. F. Durand, E. A. Eargas Jr., and L. E. Vaz, "Applications of numerical limit analysis (NLA) to stability problems of rock and soil masses," International Journal of Rock Mechanics \& Mining Sciences, vol. 43, no. 3, pp. 408-425, 2006.

[30] Z. P. Meng, S. P. Peng, and H. Li, "Influence of normal faults on the physical and mechanical properties of coal and the distribution of underground pressure," Journal of China Coal Society, vol. 26, no. 6, pp. 561-566, 2001, in Chinese.

[31] D. Y. Xuan and J. L. Xu, "Longwall surface subsidence control by technology of isolated overburden grout injection," International Journal of Mining Science and Technology, vol. 27, pp. 813-818, 2017.

[32] Q. Wu, L. Jiang, Q. Wu, Y. Xue, and B. Gong, "A study on the law of overburden migration and separation space evolution under hard and thick strata in underground coal mining by similar simulation," DYNA, vol. 93, no. 2, pp. 175-181, 2018.

[33] J. Wang, J. G. Ning, P. Q. Qiu, S. Yang, and H. F. Shang, "Microseismic monitoring and its precursory parameter of hard roof collapse in longwall faces: a case study," Geomechanics and Engineering, vol. 17, pp. 375-383, 2019.

[34] J. Wang, J. Ning, L. S. Jiang, J. Q. Jiang, and T. T. Bu, "Structural characteristics of strata overlying of a fully mechanized longwall face: a case study," Journal of the Southern African Institute of Mining and Metallurgy, vol. 118, pp. 1195-1204, 2018.

[35] P. Kong, L. Jiang, J. Shu, A. Sainoki, and Q. Wang, "Effect of fracture heterogeneity on rock mass stability in a highly heterogeneous underground roadway," Rock Mechanics and Rock Engineering, vol. 52, no. 11, pp. 4547-4564, 2019. 